\title{
Robots as New Tools in Therapy and Education for Children with Autism
}

\author{
Claire AGJ Huijnen ${ }^{1,2 *}$, Monique AS Lexis ${ }^{1}$ and Luc $\mathbf{P}$ de Witte ${ }^{3}$
}

${ }^{1}$ Research Centre Technology in Care, Zuyd University of Applied Sciences, Heerlen, The Netherlands

${ }^{2}$ CAPHRI School for Public Health and Primary Care, Faculty of Health, Medicine and Life Sciences, Maastricht University, Maastricht, The Netherlands

${ }^{3} \mathrm{CATCH}$ Centre for Assistive Technology and Connected Healthcare, University of Sheffield, UK

\begin{abstract}
Robots are increasingly considered as a promising tool in therapeutic and educational interventions for children with autism spectrum disorder (ASD). International literature indicates that robots can potentially be applied to a wide range of objectives. The aim of this article is to present an overview of robots that are currently used in therapy and educational for children with ASD and to indicate what objectives they address. Focus group sessions $(\mathrm{N}=9)$ with $\mathrm{ASD}$ professionals $(\mathrm{N}=53)$ from nine organisations were conducted which identified potential objectives for children with ASD. A systematic literature study delivered an overview of the state of the art of robots under study. Professionals reported to work on 74 ASD objectives in 9 different domains (based on the International Classification of Functioning - Child and Youth, ICF-CY). The robots $(\mathrm{N}=14)$ found in the literature addressed 24 of these objectives in 8 of the 9 domains, indicating the potential contribution of these robots to therapy and education of children with ASD. Domains that are targeted most often by robots currently are 'social or interpersonal interactions and relations', 'play' and 'communication'. Results indicate that robot mediated interventions are considered to be a possible valuable tool in the education or therapy for children with autism. In order to unlock the potential of robots, it is advised that technical developers use knowledge from ASD practice so that meaningful applications can be developed.
\end{abstract}

Keywords: Autism spectrum disorder (ASD); Children; Therapy and education objectives; Robots

\section{Introduction}

More and more children, about $0.66 \%$ or 1 child in 152 children, have the diagnosis of Autism Spectrum Disorder (ASD) [1-5]. Autism spectrum disorder is characterised by persistent deficits in social communication and social interaction across multiple contexts, as well as restricted, repetitive patterns of behaviour, interests, or activities [6]. It is a disorder which affects multiple areas of daily living throughout a person's life. People (children) benefit from early and on-going intervention that is tailored to their specific individual needs [5]. Technology is an accepted and efficient support tool in the therapy and education of individuals with ASD and their (informal) carers [7-10]. More, specifically, robot-assisted therapy (RAT) or robot-mediated intervention (RMI) is considered promising for children with ASD [11-16]. Although it might sound contradictory to use a robot to teach children skills in areas such as communication and social interaction, the use of robots has a number of advantages for these children. Interacting with a robot can be easier for them than interacting with a person, but also less complex, more predictable, simpler and more appealing; robots can be applied in a controlled manner which decreases the risk of stressful situations; robots are better in endless repetitions and variations can be made in a conscious and controlled way $[8,17]$. The aim of this short commentary is to provide a short overview of robots for use in ASD interventions as presented in the literature.

\section{Methods}

A mixed method approach, including focus groups and a systematic literature study was used to create this overview. This short commentary is based on previous research [14]. Professionals $(\mathrm{N}=53)$ working in care organisations or special needs schools for children with ASD participated in 9 focus group sessions to provide insight into the objectives that are important for these children [14]. This resulted in an overview of 9 domains including 74 objectives, as presented in Figure 1. These domains, based on the ICF-CY, were: communication, social/ interpersonal interactions and relations, self-care/independent living, play, emotional wellbeing, sensory experiences and coping, motor experiences and skills, preschool skills and functioning in daily reality.
Each of these domains includes a number of specific objectives (Figure 1). A systematic literature study was conducted based on principles of the Cochrane Handbook [18] to learn more about the state of the art of robotics for this target group. The consulted databases were PubMed, CINAHL, EMBASE, ERIC, IEEE Xplore digital library, Science Direct, Springer Link and Taylor \& Francis. Furthermore, a Google Scholar search was carried out.

\section{Results}

Peer reviewed articles discussed 14 different robot platforms that focus on 24 different objectives of the 74 ASD objectives identified by the professionals. Figure 2 provides an overview of these robots and the objectives that they addressed. Some robots (e.g. NAO, Robota, Probo, Keepon, Isobot, Tito, GIPY-1, KASPAR, Ifbot, Labo-1) have been applied for multiple objectives, and other robots have been reported in the context of one ASD objective only (e.g. cat robot, HOAP 3, Robot arm and Pleo). Objectives that were studied most often were: 'imitation in social interaction', 'turn-taking,' 'imitation in play', 'collaboration/joint attention', 'playing together - collaborative play' and 'attention'. The most commonly addressed domains are: 'Social/Interpersonal interactions and relations', 'Play' and 'Communication'. The domain of 'Self-care, independent living' is left unaddressed by all robots. 'Preschool skills' is the domain for which the ASD professionals identified most objectives $(\mathrm{n}=14)$. However, only 1 of these 14 objectives was targeted, by the robot Nao ('pose a question/ask for help').

*Corresponding author: Claire AGJ Huijnen, Research Centre Technology in Care, Zuyd University of Applied Sciences, Henri Dunantstraat 2, Heerlen, 6419 PB, The Netherlands, Tel: +31(0)880272120; E-mail: claire.huijnen@zuyd.nl; chuijnen@gmail.com

Received July 10, 2017; Accepted June 28, 2017; Published August 04, 2017

Citation: Huijnen CAGJ, Lexis MAS, de Witte LP (2017) Robots as New Tools in Therapy and Education for Children with Autism. Int J Neurorehabilitation 4: 278. doi: $10.4172 / 2376-0281.1000278$

Copyright: ( 2017 Huijnen CAGJ, et al. This is an open-access article distributed under the terms of the Creative Commons Attribution License, which permits unrestricted use, distribution, and reproduction in any medium, provided the original author and source are credited. 


\section{Emotional wellbeing}

Recognise and regulate own emotions

Self-image - ASD awareness - who am I?

Resilience (detect and guard limits - defend oneself)

Confidence - self esteem

Rest - relaxation

Having fun - experiencing pleasure

Safety

Making thoughts positive

\section{Play}

Imitation

Develop interest in play

Development own play

Parallel play (next to each other SAME MATERIAL)

Playing together - collaborative play

Variation in play (expand play)

Negotiate about rules

\section{Functioning in daily reality}

Cope with unexpected situations or changes

Flexibility - switch smoothly - less rigid

Problem solving skills

Taking initiative

Transfer of skills / knowledge

Open mind to tasting / eating food

\section{Social / Interpersonal interactions and relations}

Imitation

Attention

Appropriately cope with own anger / sadness /.

Awareness of feelings wishes behaviour thoughts of others

Appropriately react to behaviour of others

Social routines (greet say goodbye introduce)

Turn taking (behaviour)

Respect / value others (or things)

Appropriate behaviour w.r.t. physical proximity / contact or personal space

Collaboration / joined attention

Ask for help

Conflict management

\section{Sensory experiences and coping}

Adequate processing of sensory triggers (regulate - mute - stimulate)

Understand what body is "saying" (e.g. pee - hunger - noises)

Change stereotype behaviour

Prevent panic reactions

Be able to postpone urge / want

\section{Preschool skills}

Work posture (sit still - no wobbling)

Train or practice skills

Be able to start/stop independently

Work on his/her own - task approach

Cope with schedule/program

Pose a question / ask for help

Distinguish main from minor issues

Follow up instructions

Execute task (simple / complex task)

Didactic subjects (e.g. maths - reading)

Spatial concepts

Learn to wait

Perseverance

Learn to choose - make decisions

\section{Motor experiences and skills}

Balance and equilibrium

Body awareness

Grove and fine motor skills

Movement

Coordination

Strengthening of muscles

\section{Communication}

Orientation to listen

Making contact

Learn a new form of communication

Understand intention of gesture

Understand intention of image / symbol

Understand intention of word

Use gesture

Use nonverbal abilities

Talk - use verbal abilities

\section{Self-care - independent living}

Potty training

Eating - drinking

(un)Dressing

Self-care - personal hygiene

Domestic skills

Mobility

Hobbies - leisure time

Figure 1: Overview of therapy and education objectives for children with autism spectrum disorder.

\begin{tabular}{|c|c|c|c|c|c|}
\hline Robot & $\begin{array}{l}\text { Therapy or educational } \\
\text { objectives }\end{array}$ & References & Robot & Therapy or educational objectives & References \\
\hline Nao & $\begin{array}{l}\text { Imitation; Attention; } \\
\text { Collaboration/joint attention; } \\
\text { Playing together-collaborative } \\
\text { play; pose a question/ask for } \\
\text { help }\end{array}$ & {$[21-28]$} & GIPY & $\begin{array}{l}\text { Development own play; Parallel play (next } \\
\text { to each other, same material) }\end{array}$ & $\begin{array}{l}{[29]} \\
{[30]}\end{array}$ \\
\hline Robota & $\begin{array}{l}\text { Imitation; Turn taking } \\
\text { (behaviour); Imitation; } \\
\text { Coordination }\end{array}$ & [31-33] & Hoap 3 & $\begin{array}{l}\text { Development own play; Parallel play (next } \\
\text { to each other, same material); Taking } \\
\text { initiative }\end{array}$ & [34] \\
\hline Probo & $\begin{array}{l}\text { Awareness of feelings, wishes, } \\
\text { behaviour, thoughts of others; } \\
\text { social routines (greet, say } \\
\text { goodbye, introduce); parallel } \\
\text { play (next to each other, same } \\
\text { material) }\end{array}$ & {$[35,36]$} & & $\begin{array}{l}\text { Making contact; Attention; Appropriately } \\
\text { react to behaviour of others; Turn taking } \\
\text { (behaviour); Appropriate behaviour w.r.t. } \\
\text { physical proximity; Playing together- } \\
\text { collaborative play; Self-image, ASD } \\
\text { awareness; Adequate processing sensory } \\
\text { triggers, regulate, stimulate; Understand } \\
\text { what body is "saying"; Be able to postpone } \\
\text { urge; Taking initiative }\end{array}$ & $\begin{array}{l}{[37]} \\
{[38]} \\
{[39]} \\
{[40]} \\
{[37]}\end{array}$ \\
\hline & $\begin{array}{l}\text { Making contact; appropriately } \\
\text { react to behaviour of others; } \\
\text { Development own play; } \\
\text { Flexibility, switch smoothly, } \\
\text { less rigid }\end{array}$ & [41-43] & $\begin{array}{l}\text { Robot } \\
\text { arm }\end{array}$ & Imitation & [44] \\
\hline $\begin{array}{l}\text { Cat } \\
\text { robot } \\
\forall\end{array}$ & $\begin{array}{l}\text { Awareness of feelings, wishes, } \\
\text { behaviour, thoughts of others }\end{array}$ & [45] & & Talk - Use verbal abilities & [46] \\
\hline I-sobot & Imitation & {$[47,48]$} & Labo-1 & Turn taking (behaviour); Imitation & {$[49,50]$} \\
\hline Tito & $\begin{array}{l}\text { Collaboration / joint attention; } \\
\text { Imitation }\end{array}$ & [51] & ifbot & $\begin{array}{l}\text { Orientation to listen; Use nonverbal } \\
\text { abilities; Talk, use verbal abilities }\end{array}$ & [52] \\
\hline
\end{tabular}

Figure 2: Overview of robots and objectives they may address. 
For the domain of 'Emotional wellbeing' also one robot (KASPAR) could be identified in one article addressing one objective ('self-image, ASD awareness, who am I').

Recent research aimed to study the expectations of professionals of what contribution robot KASPAR can have for children with autism. Professionals expect that KASPAR can contribute mostly to working on objectives in the domains of communication, social interaction, and play [19]. Examples of objectives in these domains are: 'imitation in play', 'making contact', 'orientation to listen', 'imitation in social interaction and relations', 'turn taking', 'social routines', 'attention', 'learn a new form of communication' and 'talk - use verbal abilities'. Professionals also expect KASPAR to contribute to objectives in other domains such as emotional wellbeing and preschool skills: 'having fun, experiencing pleasure', 'develop interest in play' or 'train or practice skills,' 'pose a question or ask for help' and 'follow up instructions' [19].

These results indicate that robot mediated interventions may address a larger scope of objectives for these children than they currently do. Although more and more studies highlight the potential of robots for this target group, robots have not made their way into (many) classrooms or therapy sessions yet. Many of the robots found in the literature are still in a prototype stage and not commercially available. It is highly recommended that knowledge from ASD practice reaches technical robot developers to guide robot development so that studies can be conducted with robot interventions that are carefully designed to meet the specific needs of this target group and that utilise the potential power of robots [20].

\section{References}

1. Blaxill MF (2004) What's going on? The question of time trends in autism Public Health Rep 119: 536-551.

2. Olds J, Rubin P, MacGregor D, Madou M, McLaughlin A, et al. (2013) Implications: Human cognition and communication and the emergence of the cognitive society. In: Convergence of Knowledge, Technology and Society SE - 6, M.C. Roco, W.S. Bainbridge, B. Tonn and G. Whitesides, Eds. Springer International Publishing, pp: 223-253.

3. Scasselatti B (2005) Paper presented at the IEEE Workshop on Robots and Human Interactive Communications.

4. Wong C, Odom SL, Hume KA, Cox AW, Fettig A, et al. (2015) Evidence-based practices for children, youth and young adults with autism spectrum disorder: $A$ comprehensive review. J Autism Dev Disord 45: 1951-1966.

5. Volkmar FR, Paul R, Rogers SJ (2014) Handbook of autism and pervasive developmental disorders: Diagnosis, development and brain mechanisms. John Wiley \& Sons 1

6. American Psychiatric Association (2013) Diagnostic and statistical manual of mental disorders (DSM-5®). American Psychiatric Pub.

7. Aresti-Bartolome N, Garcia-Zapirain B (2014) Technologies as support tools for persons with autistic spectrum disorder: A systematic review. Int J Environ Res Public Health 11: 7767-7802.

8. Boucenna S, Narzisi A, Tilmont E, Muratori F, Pioggia G, et al. (2014) Interactive technologies for autistic children: A review. Cognit Comput 6: 722-740.

9. Grynszpan O, Weiss PL, Perez-Diaz F, Gal E (2014) Innovative technologybased interventions for autism spectrum disorders: A meta-analysis. Autism 18: 346-361.

10. Lee $H$, Hyun $E$ (2015) The intelligent robot contents for children with speechlanguage disorder. Educ Technol Soc 18: 100-113.

11. Begum M, Serna RW, Yanco HA (2016) Are robots ready to deliver autism interventions? A comprehensive review. Int J Soc Robot 8: 157-181.

12. Cabibihan J, Javed H, Ang M, Aljunied S (2013) Why robots? A survey on the roles and benefits of social robots in the therapy of children with autism. Int $\mathrm{J}$ Soc Robot 5: 593-618.

13. Diehl JJ, Schmitt LM, Villano M, Crowell CR (2012) The clinical use of robots for individuals with autism spectrum disorders: A critical review. Res Autism Spectr Disord 6: 249-262.

14. Huijnen CAGJ, Lexis MAS, Jansens R, de Witte LP (2016) Mapping robots to therapy and educational objectives for children with autism spectrum disorder. J Autism Dev Disord 46: 2100-2114

15. Pennisi P, Tonacci A, Tartarisco G, Billeci L, Ruta L, Gangemi S, Pioggia G (2016) Autism and social robotics: A systematic review. Autism Res 9: 165-183.

16. Scassellati B, Admoni H, Matarić M (2012) Robots for use in autism research. Annu Rev Biomed Eng 14: 275-294

17. Thill S, Pop CA, Belpaeme T, Ziemke T, Vanderborght B (2012) Robot-assisted therapy for autism spectrum disorders with (partially) autonomous control: Challenges and outlook. Paladyn J Behav Robot 3: 209-217.

18. Higgins J, Green S (2011) Cochrane handbook for systematic reviews of interventions. Wiley Online Library 5.

19. Huijnen CAGJ, Lexis MAS, de Witte LP (2016) Matching robot KASPAR to autism spectrum disorder (ASD) therapy and educational goals. Int J Soc Robot 8: 445-455.

20. Huijnen CAGJ, Lexis MAS, Jansens R, de Witte LP (2017) How to implement robots in interventions for children with autism? A co-creation study involving people with autism, parents and professionals. J Autism Dev Disord, pp: 1-18.

21. Warren Z, Zheng Z, Das S, Young EM, Swanson A, et al. (2015) Brief report: Development of a robotic intervention platform for young children with ASD. $J$ Autism Dev Disord 45: 3870-3876.

22. Warren ZE, Zheng Z, Swanson AR, Bekele E, Zhang L, et al. (2015) Can robotic interaction improve joint attention skills? J Autism Dev Disord 45: 3726-3734.

23. Tapus A, Peca A, Aly A, Pop C, Jisa L, et al. (2012) Children with autism social engagement in interaction with $\mathrm{Nao}$, an imitative robot - A series of single case experiments. Interact Stud 13: 315-347.

24. Anzalone SM, Tilmont E, Boucenna S, Xavier J, Jouen AL, et al. (2014)How children with autism spectrum disorder behave and explore the 4-dimensional (spatial 3D+time) environment during a joint attention induction task with a robot. Res Autism Spectr Disord 8: 814-826.

25. Bekele E, Crittendon JA, Swanson A, Sarkar N, Warren ZE (2014) Pilot clinica application of an adaptive robotic system for young children with autism. Autism 18: $598-608$

26. Huskens B, Palmen A, Van der Werff M, Lourens T, Barakova E (2014) Improving collaborative play between children with autism spectrum disorders and their siblings: The effectiveness of a robot-mediated intervention based on lego therapy. J Autism Dev Disord 45: 3746-3755.

27. Huskens B, Verschuur R, Gillesen J, Didden R, Barakova E (2013) Promoting question-asking in school-aged children with autism spectrum disorders: Effectiveness of a robot intervention compared to a human-trainer intervention. Dev Neurorehabil 16: 345-356.

28. Bekele E, Young M, Zheng Z, Zhang L, Swanson A, et al. (2013) A step towards adaptive multimodal virtual social interaction platform for children with autism. LNCS, no. PART 2, C. Stephanidis and M. Antona, Eds. Springer Berlin Heidelberg, pp: 464-473.

29. Giannopulu I, Pradel G (2012) From child-robot interaction to child-robottherapist interaction: A case study in autism. Appl Bionics Biomech 9: 173-179.

30. Giannopulu I, Pradel G (2010) Multimodal interactions in free game play of children with autism and a mobile toy robot. Neurorehabilitation 27: 305-311.

31. Billard A, Robins B, Nadel J, Dautenhahn K (2007) Building Robota, a minihumanoid robot for the rehabilitation of children with autism. Assist Techno 19: $37-49$

32. Robins B, Dautenhahn K, Dubowski J (2006) Does appearance matter in the interaction of children with autism with a humanoid robot? Interact Stud 7: 509542.

33. Robins B, Dautenhahn K, Te Boekhorst R, Billard A (2005) Robotic assistants in therapy and education of children with autism: Can a small humanoid robot help encourage social interaction skills? Univers Access Inf Soc 4: 105-120.

34. Fujimoto I, Matsumoto T, de Silva PRS, Kobayashi M, Higashi M (2011) Mimicking and evaluating human motion to improve the imitation skill of children with autism through a robot. Int J Soc Robot 3: 349-357.

35. Pop CA, Simut R, Pintea S, Saldien J, Rusu A, et al. (2013) Can the social robot 
Citation: Huijnen CAGJ, Lexis MAS, de Witte LP (2017) Robots as New Tools in Therapy and Education for Children with Autism. Int J Neurorehabilitation 4: 278 . doi: $10.4172 / 2376-0281.1000278$

probo help children with autism to identify situation-based emotions? A series of single case experiments. Int J Humanoid Robot 10: 1350025

36. Vanderborght B, Simut R, Saldien J, Pop C, Rusu AS, et al. (2012) Using the social robot probo as a social story telling agent for children with ASD. Interact 13: $348-372$

37. Wainer J, Dautenhahn K, Robins B, Amirabdollahian F (2014) A pilot study with a novel setup for collaborative play of the humanoid robot KASPAR with children with autism. Int J Soc Robot 6: 45-65

38. Wainer J, Robins B, Amirabdollahian F, Dautenhahn K (2014) Using the humanoid robot KASPAR to autonomously play triadic games and facilitate collaborative play among children with autism. IEEE Trans Auton Ment Dev 6: 183-199.

39. Robins B, Dautenhahn K (2014) Tactile Interactions with a humanoid robot Novel play scenario implementations with children with autism. Int J Soc Robot 6: 397-415.

40. Costa S, Lehmann H, Dautenhahn K, Robins B, Soares F (2015) Using a humanoid robot to elicit body awareness and appropriate physical interaction in children with autism. Int J Soc Robot 7: 265-278.

41. Kozima H, Nakagawa C, Yasuda Y (2007) Children-robot interaction: A pilo study in autism therapy. Prog Brain Res 164: 385-400.

42. Kozima H, Michalowski MP, Nakagawa C (2009) Keepon: A playful robot for research, therapy and entertainment. Int J Soc Robot 1: 3-18.

43. Costescu CA, Vanderborght B, David DO (2014) Reversal learning task in children with autism spectrum disorder: A robot-based approach. J Autism Dev Disord 45: 3715-3725.
44. Pierno AC, Mari M, Lusher D, Castiello U (2008) Robotic movement elicits visuomotor priming in children with autism. Neuropsychologia 46: 448-454.

45. Mun KH, Kwon JY, Lee BH, Jung JS (2014) Design developing an early model of cat robot for the use of early treatment of children with autism spectrum disorder (ASD). Int J Control Autom 7: 59-74.

46. Kim ES, Paul R, Scassellati B, Bernier EP, Leyzberg D, et al. (2013) Socia robots as embedded reinforcers of social behavior in children with autism. $J$ Autism Dev Disord 43: 1038-1049.

47. Srinivasan SM, Lynch KA, Bubela DJ, Gifford TD, Bhat AN (2013) Effect of interactions between a child and a robot on the imitation and praxis performance of typically devloping children and a child with autism: A preliminary study. Percept Mot Skills 116: 885-904.

48. Kaur M, Gifford T, Marsh KL, Bhat A (2013) Effect of robot-child interactions on bilateral coordination skills of typically developing children and a child with autism spectrum disorder: A preliminary study. J Mot Learn Dev 1: 31-37.

49. Dautenhahn K (2004) Socially intelligent robots: Dimensions of human-robot interaction. Philos Trans R Soc Lond B Biol Sci 362: 679-704.

50. Dautenhahn K, Werry I (2004) Towards interactive robots in autism therapy: Background, motivation and challenges. Pragmat Cogn 12: 1-35.

51. Duquette A, Michaud F, Mercier H (2008) Exploring the use of a mobile robot as an imitation agent with children with low-functioning autism. Auton Robots 24: 147-157.

52. Lee J, Takehashi H, Nagai C, Obinata G, Stefanov D (2012) Which robot features can stimulate better responses from children with autism in robotassisted therapy? Int J Adv Robot Syst 9. 